\title{
Of Microsoft and mycobacteria
}

\author{
Hans Pasterkamp MD FRCPC \\ Section of Respirology, Department of Pediatrics and Child Health \\ University of Manitoba, Winnipeg, Manitoba
}

B ill Gates should have run for President of the United States. Not only would he have been a candidate with some legitimate claim to the Internet, but his call for a major increase in funding for new defence systems would have been supported by the general public, both at home and abroad. The founder of Microsoft himself spent US\$1.44 billion last year to support the fight against global health threats from infectious diseases such as AIDS, malaria and tuberculosis (TB). This contribution from the Bill and Melinda Gates Foundation was more than one-quarter of the total amount that all industrialized nations together raised for this cause.

There is no question that there is a threat posed by the invisible forces of mycobacteria and that we have an escalating arms race with this enemy. Globally, TB is the second leading cause of death from an infectious disease, taking almost three million lives per year. Seven years ago, the World Health Organization declared TB a global emergency. Today, there is no sign that, globally, we are winning the war against TB, even though regional success may offer a sense of achievement. In Canada, the incidence of TB has declined, even after the World Health Organization declared it a worldwide emergency. Now, almost two-thirds of the roughly 2000 Canadian cases of TB per year are found in immigrants (1).

Most Canadians have not had personal experience with $\mathrm{TB}$, but the threat of infection remains real. An immigrant from the Dominican Republic, who recently entered Canada carrying a drug-resistant strain of $\mathrm{TB}$, may have been in contact with more than 1500 people in Ontario. Tests so far have shown that 92 contacts possibly were infected. Drug resistance and coexisting infection with HIV are now escalating the danger of TB. While drug-resistant TB remains relatively rare in Canada, in immigrants from Asia, the rate of resistance to single drugs is $15 \%$ to $20 \%$ and the rate of resistance to multiple drugs may exceed $1 \%$. Ten years ago, only $4 \%$ of TB cases were attributable to HIV, but this proportion has risen to $14 \%$. In most cases, the chance to contract and transmit HIV can be minimized by avoiding a high risk lifestyle. However, TB can spread through casual contact.

Many people are familiar with the crowded and confined environment of commercial airline carriers. Some carefully conducted studies have shown that TB transmission and infection during air travel have almost certainly occurred (2): frequent flyers beware. When the rules of engagement change and TB is spread by young children, even the school bus becomes a dangerous environment. This was the case in North Dakota, where a nine-year-old boy from the Marshall Islands was found to have bilateral cavitary $\mathrm{TB}$, but not before three-quarters of his classroom contacts and one-third of the children on his bus had become infected (3).

Considering the 'taxes' that most pay to Mr Gates as users of his Microsoft products, one has to appreciate the enlightened view on spending that he has shown in his unelected position. Mr Gates has pledged US\$1 billion annually throughout his lifetime to be spent on global health issues. It is estimated that in New York City alone, it has cost US $\$ 1$ billion to reverse the resurgence of TB that occurred after the federal funding that had been targeted to TB was eliminated in the 1980s. Last year in May, the Institute of Medicine (IOM) laid out an action plan to eliminate TB in the United States, ie, to reduce the incidence rate of TB from 70 cases per million per year, which it is currently, to less than one case per million per year. The report, entitled Ending Neglect (4), calls for several steps of concerted effort involving all levels of government and the private sector.

Next year, the IOM action plan for the fight against TB will cost the Americans more than US\$500 million. A similar amount in Canadian dollars was demanded in a class action lawsuit that was filed against the Canadian government by the immigrant from the Dominican Republic, his wife and two other infected individuals for its negligence and failure to test properly during the immigration procedure. Citizenship and Immigration Minister Elinor Caplan has ordered an audit of the worldwide network of 1700 physicians who are responsible for the screening of immigrants to Canada. Beginning this fall, immigrants will have to undergo more stringent medical examinations; this screening will also apply to visitors who are staying in Canada for more than six months.

According to the IOM action plan, it is necessary for the United States federal government to provide adequate fund- 
ing specifically targeted at TB. Further steps in the IOM plan are: developing targeted programs that use skin testing to detect latent $\mathrm{TB}$; developing more effective methods to identify infection among contacts; expanding research; encouraging business to develop TB-related products; promoting the regionalization of TB services to cover larger geographic areas; supporting national training programs; and educating TB patients and their families.

To a large extent, these recommendations are not specific to the United States, and can apply to Canada and other countries. However, when examining the regionalization of services, the federal and provincial governments in Canada have begun to define regional health authorities on a much smaller scale. Considering the high rate of TB among the Aboriginal people of Canada, which is still three to 10 times the rate of non-Aboriginal persons born in this country, the transition of health care authority from the federal government to the governing bodies of individual First Nations carries a risk of the less efficient use of clinical, epidemiological and other technical services.

Targeted programs for tuberculin skin testing in this high incidence population are of diminished usefulness because of bacille Calmette-Guérin (BCG) vaccination. This is the most popular vaccine in the world, received by more than $80 \%$ of the world's population, and is a prime example of the hopeless aspirations of evidence-based medicine. Efficacy data from more than 20 controlled trials vary widely, and efficacy rates range from $0 \%$ to almost $80 \%$. The most convincing protection is provided to young children who have lower rates of miliary and meningeal $\mathrm{TB}$ when vaccinated with BCG. There are now 18 different strains of the vaccine, and several strains have undergone a decline in efficacy during many years of in vitro passage. Because of this decline in efficacy and other factors, countries in the European community have adopted various policies regarding BCG vaccination, ranging from the obligatory vaccination of children (in France) to the exclusion of the vaccine from paid services and the active discouragement of BCG vaccination (in Germany). Interestingly, this has not led to significant differences in the epidemiology of $\mathrm{TB}$, even among neighbouring countries.

Even public health experts acknowledge that for TB, the cure may be better than the prevention. The key to the ultimate eradication of TB is the reduction of infections, and it is obvious that BCG vaccination has failed in this regard. A review of the epidemiological basis for policy decisions to vaccinate Canadian Aboriginal persons acknowledged that the use of BCG may be redundant, even if it is effective. There was a recommendation to test formally whether the BCG vaccination should be discontinued in selected communities to establish firm evidence for or against its use (5). Sixteen years later, this information is still not available.

We are in a position in which money can buy effective weapons, and pay for strategies to fight and ultimately eradicate tuberculosis. New drugs and preparations that shorten and simplify treatment, new methods to trace infections by genetic traits of the mycobacteria, and new vaccines to provide clear benefit in the prevention of the disease are advancing in development. In dealing with the global TB emergency, Canada can offer expertise in a most important area: the use of telemedicine and distance education. The situation is poor for medical and diagnostic services in many Asian and African countries, which are the home of most of the Canadian immigrants. The strategic use of information technology could advance medical practice in these areas to a more even standard, which would go a long way toward the identification and treatment of TB.

Bill Gates has called on the world's industrialized nations to show a greater commitment to fight the global threat of infectious diseases. His own contributions are admirable, but let's face it - at Microsoft, he has other bugs and viruses to worry about. The governments of Canada and other wealthy nations should not rely on funding by computer users alone but must begin to tackle the global emergency of TB seriously.

\section{REFERENCES}

1. Canadian Lung Association. Canadian Tuberculosis Standards, 5th edn. <http://www.lung.ca/tb/TBStandards_Eng.pdf> (Date of access March 2000)

2. WHO guidelines seek to lower risk of TB transmission during air travel. Public Health Rep 1999;114:101.

3. Curtis AB, Ridzon R, Vogel R, et al. Extensive transmission of Mycobacterium tuberculosis from a child. N Engl J Med 1999;341:1491-5.

4. Geiter L, ed. Ending Neglect: The Elimination of Tuberculosis in the United States. Washington: National Academy Press, 2000.

<http://www.nap.edu/catalog/9837.html?send> (Date of access March 2000)

5. Young TK. BDG vaccination among Canadian Indians and Inuit: the epidemiological bases for policy decision. Can J Public Health 1985;76:124-9. 


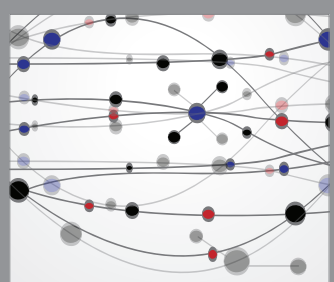

The Scientific World Journal
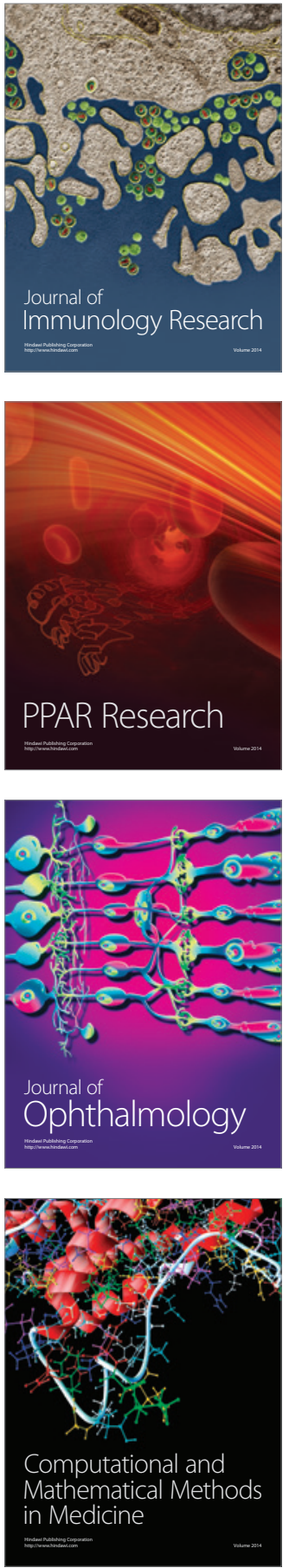

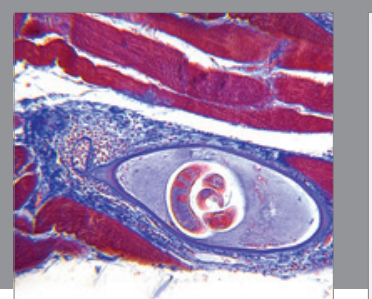

Gastroenterology Research and Practice

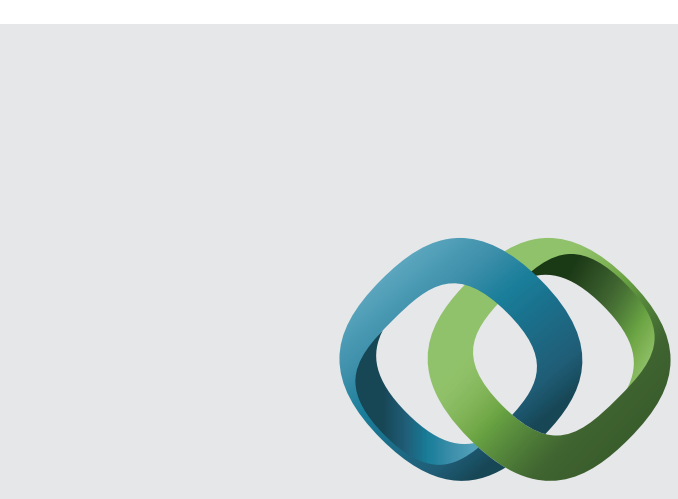

\section{Hindawi}

Submit your manuscripts at

http://www.hindawi.com
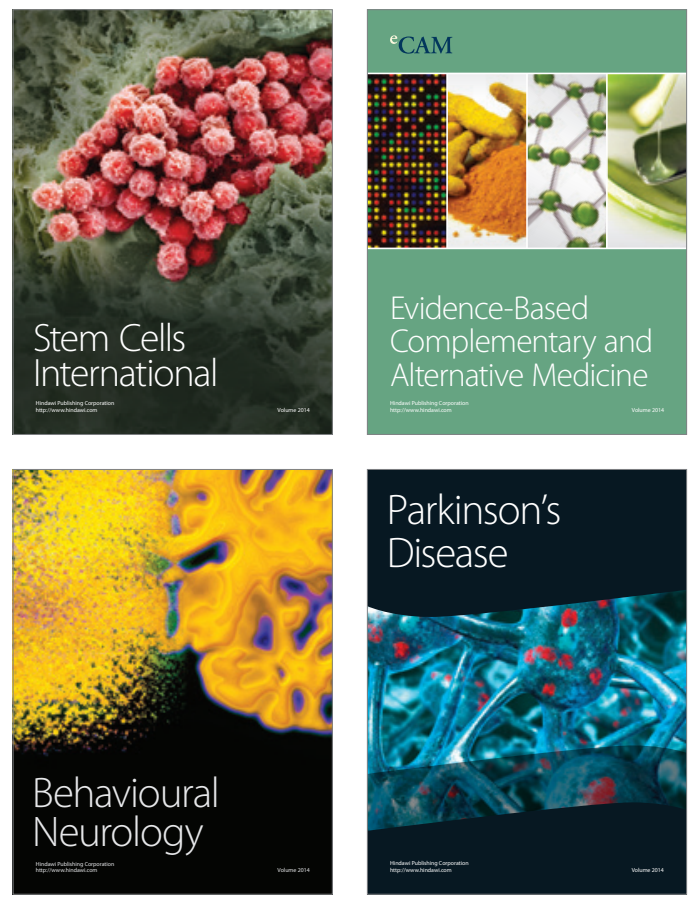
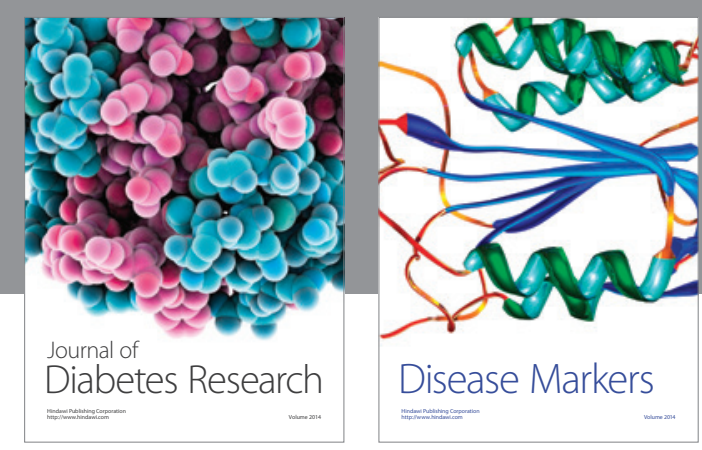

Disease Markers
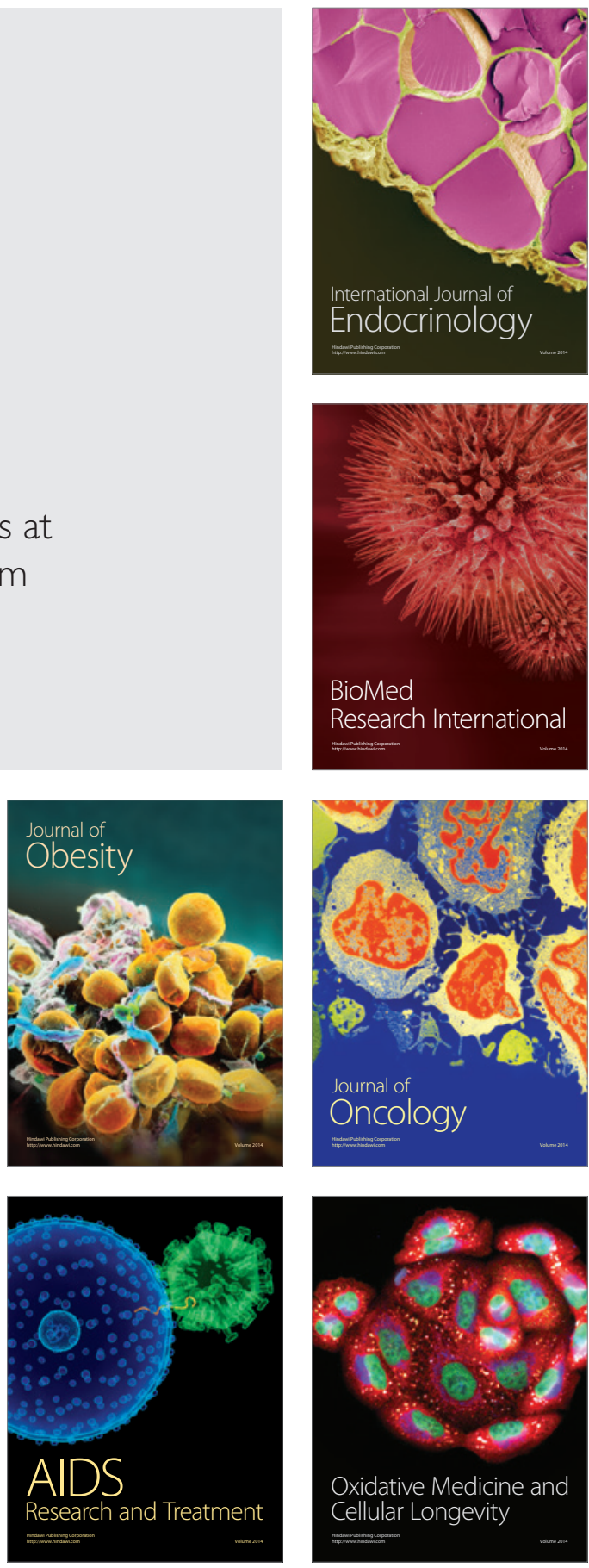